\title{
Measuring Chinese Risk Aversion Based on Insurance Data
}

\author{
Li Diao \\ School of Insurance, \\ Central University of Finance and Economics, \\ Beijing, China.
}

\begin{abstract}
In the literature risk aversion has been widely studied by many scholars. However, little research is done about China's market. In this paper we assume a model involves the insurance data and estimate the risk aversion in China. We use data from 1997 to 2013 after modifying by deflators. The result comes out to support our hypothesis of increasing relative risk aversion.
\end{abstract}

Keywords: Risk Aversion; Insurance Data; Risk Management.

\section{INTRODUCTION}

There is a consensus that absolute risk aversion decreases with wealth. It was established by Pratt (1964) and Arrow (1965), along with the measure of absolute and relative risk aversion. Many other studies have tried to derive similar hypothesis about relative risk aversion, but their results vary widely. Such studies include Friend and Blume (1975), Siegel and Hoban (1982), Morin and Suarez (1983), Szpiro (1986), Blake (1996), etc.

Szpiro (1986) used the time series data from 1955 to 1975 on property/ liability insurance in the United States and concluded that relative risk aversion was constant and the degree was between about 1.2 to 1.8 .

In this paper we use similar model and analyze the risk aversion in China. First, we assume a risk aversion function revolves some variables and parameters. We modify the time series data by deflators and do nonlinear regression. Then we choose the parameters which have the minimum sum of squared errors and evaluate the coefficient of China's risk aversion.

According to the result, we conclude that the relative risk aversion in China increases with wealth. Our result conforms to the hypothesis of IARA (increasing relative risk aversion.).

\section{Model}

\section{MATERIALS AND METHODS}

We assume that the amount of insured assets has a form like:

$$
I=W-\lambda / r(W)
$$

where $I$ is the insured assets, $W$ is the individual's wealth, $\lambda$ is the loading charged by insurance companies, and $r(W)$ donates the absolute risk aversion.

Denote $P=p \cdot I$ and $Q=q \cdot I$ respectively, because the amount insured assets $I$ cannot be obtained directly. Here $P$ is the total premiums, $p$ donates the premium rate. $Q$ is the total premiums, $q$ donates the premium rate. Then we get a couple of equations:

$$
\begin{aligned}
& P=p \cdot W-p \cdot \lambda / r(W) \\
& Q=q \cdot W-q \cdot \lambda / r(W)
\end{aligned}
$$


We assume the risk aversion function has the form:

$$
r(W)=c / W^{h}
$$

Substituting equation (4) into (2) and (3), we get:

$$
\begin{aligned}
& P_{t}=p \cdot W_{t}-p \cdot \frac{1}{c}\left(\lambda_{t} W_{t}^{h}\right)=a \cdot W+m\left(\lambda_{t} W_{t}^{h}\right) \\
& Q_{t}=q \cdot W_{t}-q \cdot \frac{1}{c}\left(\lambda_{t} W_{t}^{h}\right)=b \cdot W+n\left(\lambda_{t} W_{t}^{h}\right)
\end{aligned}
$$

We choose the parameters which results the minimum S.E. of regression and use them to evaluate the coefficient of relative risk aversion. Set the range of $h$ from -5 to 5 . The step size is 0.01 . By nonlinear regression we obtain the value of $h$, together with those for $a, m, b$ and $n$. Moreover, there are some restriction conditions. The results should subject to $a>0, b>0$, $m<0$ and $n<0$. Because of $a=p$ and $p$ stands for the premium rate, there must be $a>0$. So does to $b$. Generally, we agree that the coefficient of absolute risk aversion is positive. Then because of $r(W)=c / W^{h}>0$, and our results prove $h>0$, so we have $c>0 . m=-p / c$, so $m<0$. So does to $n$.

\section{Data Acquiring and Processing}

In order to conduct the empirical study, we need the premiums data $P$, claims data $Q$, the individual's wealth $W$ and premium loading $\lambda$. Considering the availability of data, take the GDP per capita as individual's wealth. Use $(P / Q)-1$ as $\lambda$.

The data after modified by fixed base CPI are presented in Table1.

Table1. Data after modified.

\begin{tabular}{c|c|c|c|c}
\hline Year & $\mathrm{P}$ & $\mathrm{Q}$ & $\mathrm{W}$ & $\lambda$ \\
\hline 2001 & 10.14766 & 5.504403 & 1972.93 & 0.84355324 \\
2002 & 11.18747 & 5.940737 & 2167.948 & 0.8831788 \\
2003 & 12.42772 & 6.45758 & 2403.002 & 0.92451661 \\
2004 & 14.26367 & 7.387239 & 2706.358 & 0.93085265 \\
2005 & 16.14889 & 8.49713 & 3057.19 & 0.90051111 \\
2006 & 18.55891 & 9.947859 & 3503.122 & 0.86561852 \\
2007 & 21.88552 & 11.63979 & 4086.196 & 0.88023323 \\
2008 & 25.55093 & 14.0459 & 4535.626 & 0.81910237 \\
2009 & 30.10224 & 16.63557 & 4934.014 & 0.80951058 \\
2010 & 36.87963 & 19.29903 & 5598.778 & 0.9109577 \\
2011 & 44.13377 & 22.40667 & 6229.697 & 0.96967108 \\
2012 & 51.59049 & 26.44391 & 6634.374 & 0.95094031 \\
2013 & 60.20909 & 30.85589 & 7045.66 & 0.95129974
\end{tabular}

\section{RESULTS}

The minimum S.E. of regression is obtained for $h_{p}=0.11$ and $h_{q}=0.18$ using premiums and claims as dependent variable. The signs of $a$ and $b$ are positive and the signs of $m$ and $n$ are negative, which meet the requirements. 
The regression result using premiums as dependent variable is shown in Figure 1.

Figure1. Results of premiums regression.

\begin{tabular}{lrlrr}
\hline \hline \multicolumn{1}{c}{ Variable } & Coefficient & Std. Error & t-Statistic & Prob. \\
\hline \hline \multicolumn{1}{c}{ W } & 0.009451 & 0.000787 & 12.01005 & 0.0000 \\
L*W^0.11 & -5.665239 & 1.601660 & -3.537105 & 0.0047 \\
\hline \hline R-squared & 0.945392 & Mean dependent var & 27.16046 \\
Adjusted R-squared & 0.940427 & S.D. dependent var & 16.41609 \\
S.E. of regression & 4.006761 & Akaike info criterion & 5.754482 \\
Sum squared resid & 176.5955 & Schwarz criterion & 5.841397 \\
Log likelihood & -35.40413 & Hannan-Quinn criter. & 5.736617 \\
Durbin-Watson stat & 0.331977 & & \\
\hline \hline
\end{tabular}

The regression result using claims as dependent variable is shown in Figure 2.

Figure2. Results of claims regression.

\begin{tabular}{lrlrr}
\hline \multicolumn{1}{c}{ Variable } & Coefficient & Std. Error & t-Statistic & Prob. \\
\hline \hline \multicolumn{1}{c}{ W } & 0.004986 & 0.000381 & 13.08354 & 0.0000 \\
L*W^0.18 $^{\prime}$ & -1.700558 & 0.432871 & -3.928555 & 0.0024 \\
\hline \hline R-squared & 0.958861 & Mean dependent var & 14.23552 \\
Adjusted R-squared & 0.955121 & S.D. dependent var & 8.336499 \\
S.E. of regression & 1.766052 & Akaike info criterion & 4.116008 \\
Sum squared resid & 34.30834 & Schwarz criterion & 4.202924 \\
Log likelihood & -24.75405 & Hannan-Quinn criter. & 4.098143 \\
Durbin-Watson stat & 0.380719 & & \\
\hline \hline
\end{tabular}

Then we estimate the coefficient of relative risk aversion.

$$
\begin{aligned}
& c_{p}=-a / m=0.001668 \\
& c_{q}=-b / n=0.002932
\end{aligned}
$$

The results are presented in Table2.

Table2. Relative risk aversion. ${ }^{1}$

\begin{tabular}{l|l|c|c}
\hline Year & \multicolumn{1}{|c|}{$\mathrm{W}$} & $\boldsymbol{r}_{\boldsymbol{p}}$ & $\boldsymbol{r}_{\boldsymbol{q}}$ \\
\hline 2001 & 1972.93 & 1.428386 & 1.476235 \\
2002 & 2167.948 & 1.553387 & 1.594865 \\
2003 & 2403.002 & 1.702422 & 1.735331 \\
2004 & 2706.358 & 1.892426 & 1.913021 \\
2005 & 3057.19 & 2.109274 & 2.114114 \\
2006 & 3503.122 & 2.38101 & 2.363836 \\
2007 & 4086.196 & 2.730675 & 2.681919 \\
2008 & 4535.626 & 2.996423 & 2.921504 \\
2009 & 4934.014 & 3.229567 & 3.130316 \\
2010 & 5598.778 & 3.61409 & 3.472165 \\
2011 & 6229.697 & 3.9744 & 3.789892 \\
2012 & 6634.374 & 4.203374 & 3.990616 \\
2013 & 7045.66 & 4.434517 & 4.192371
\end{tabular}

The changing tendency shows that the coefficient of relative risk aversion increases gradually with wealth.

1 We use five-year moving averages as proxies of annul premiums and claims, so the data start from 2001, not 1997 as mentioned before. 


\section{CONCLUSION}

Increasing relative risk aversion means that the wealthier the man, the more risk-aversion he is. In this paper IRRA means that people get richer with the time. Moreover, they purchase insurance in a much faster increasing rate. We analyze the data on property insurance and try to explain the results by the following reasons from the insurance point of view.

The first reason is the external uncertainty increasing. In past two decades, great changes have taken place in China. With the blooming of economy and technology, many kinds of new risk are appearing, and the degree of loss is also increasing. For example, every 100 families had only 0.34 cars on average in 1999. This number is increased sharply to 16.9 in following 14 years. It is well known that more vehicles mean more possibilities of risk.

Moreover, the accumulation of wealth also affects risk aversion coefficient. On one hand, the accumulation of personal property, family property and enterprise property suffer more loss than in the past when some accident occurs. On the other hand, the influence of wealth on risk aversion coefficient can be classified. Some studies indicate that house property has positive effect on risk aversion coefficient and financial property has negative effect. Thus, the more house property, the more risk aversion. In china, the price of house grew in incredible speed. According to National Bureau of statistic, the average price of commercial house was 2053 Yuan in 1999, but it was up to 6237 Yuan in 2013. People have to pay much more for house, which is about $22.7 \%$ of family income. The house property increased a lot, which means risk aversion coefficient is larger.

Another reason may be the perfection of insurance industry in China. Since 1990s, China's insurance industry is developing rapidly. It's becoming more professional, international and standardized. The sorts of insurance products have been diversified and specialized. Moreover, the quality of service has also been improved. Now the insurance needs for different people can be met.

What's more, Chinese people's understanding of risk is becoming comprehensive and profound. Now they think insurance is much more important than in the past, as it is an effective way to protect them from risk.

There are still some open problems to be solved later. First, we cannot determine the specific reasons that result IRRA in China. Second, we can't distinguish how much each factor has the effect. Finally, it is necessary to do cross-section estimates to examine our results.

\section{References}

Aldo Montesano, 1991, Measures of risk aversion with expected and nonexpected utility, Journal of Risk and Uncertainty, Vol. 4, No. 3, pp. 271-283.

George G. Szpiro, 1986, Measuring risk aversion: an alternative approach, The Review of Economics and Statistics, Vol. 68, No. 1 (Feb., 1986), pp. 156-159.

Haim Levy and Azriel Levy, 1991, Arrow-Pratt measures of risk aversion: the multivariate case, International Economic Review, Vol. 32, No. 4 (Nov., 1991), pp. 891-898.

Yulong Zhou, 2014, Wealth shocks and relative risk aversion, [D], Xiamen University. 